\title{
Patent Granting on Marine DNA Discovery
}

\author{
Khoa Tran \\ II Year Student B.A. Legal Studies, University Abu Dhabi, Saadiyat Marina District, Abu Dhabi \\ United Arab Emirates
}

\begin{abstract}
In recent years, the world has experienced various medical treatments originates from the ocean, such as cytarabine, vidarabine, and ziconotide. Marine represents a great source of species with potential medical treatments due to these species' unique properties; however, the research and discovery of this industry demand high financial resources and time management. Hence, the international government has employed intellectual property rights and patent granting as a mechanism to promote innovative research. This paper explores the benefits and disadvantages of patent granting on marine DNA discovery and application.
\end{abstract}

Keywords: Biomimicry, DNA, Intellectual Property Rights, Marine, Medicine.

\section{Introduction}

Nature is a complex but miracle system with various shapes, functions, and structures that are highly applicable in our modern lives and far more sustainable and efficient than human most cuttingedge technology. Therefore, over the last ten years, biomimicry has become a trend of bio-engineering and innovation across disciplines, ranging from robotic to business management. Many real-world applications are already available for human usages, such as the bullet train in Japan, superhydrophobic raincoat, temperature regulating systems in the commercial building, and lean business strategies. Applying biomimicry in innovation is highly recommended for a sustainable world, but it also comes with a legal question: can a company patent and own a product or a discovery from nature? To create a comprehensive picture of this legal issue, firstly, the essay will introduce the context of Marine pharmacology and the impacts of marine discovery on medical research. Moreover, it is essential to understand the nature of intellectual property rights and patent rights. Finally, this essay will explore the benefits and drawbacks of granting patent rights for a person, business, or research entities within the context of sea life.

Marine Research and Contribution to Medical and Pharmaceutical Studies: Marine represents a great source of species with potential medical solutions due to these species' unique properties. For example, according to research from Arizona State University, the Whale can defy cancer due to their excellent genes. If the researchers can decode the Whale's gene and manufacturing drugs based on the Whale's gene properties, a human would find a cure to combat the cancer problems ${ }^{1,5}$. The application of marine research in pharmacies can be categorized into three sections:

1. Genetically engineered marine organisms

2. Manufacture of pharmaceuticals and nutraceuticals of marine origin

3. Chemicals produced by or found in marine organisms shown to have a wide variety of applications as pharmaceuticals

Currently, there are many drugs application with the marine origin, such as

1. Cytarabine (Cytosar-UW, DepocytW) to treat leukemia,

2. Vidarabine (Vira-AW) to combat against herpes viruses, rhabdoviruses, hepadnaviruses, and RNA tumor viruses,

3. Ziconotide (PrialtW) as a pain reliever ${ }^{5}$.

As marine research has provided breakthrough research on medical and pharmaceutical studies, the international government must develop a mechanism that promotes such research globally. One solution is granting patent and intellectual property rights. 
Intellectual Property and Patent Granting: According to the World Intellectual Property Organization (WIPO), "intellectual property (IP) refers to creations of the mind, such as inventions; literary and artistic works; designs; and symbols, names, and images used in commerce." A patent is "an exclusive right granted for an invention, which is a product or a process that provides, in general, a new way of doing something, or offers a new technical solution to a problem." The IP rights and patent specifically aim to balance the inventors' interests and public interests; thus, they nourish the fair-use, innovative environment, and credit creativity. When an inventor patents an invention, he must share the technical information with the public, and he will get back the rights to prevent others from using his invention without permission. Based on WIPO's definition, one can only fill a patent for "a new way of doing something" or "a new technical solution to a problem"; hence, one cannot patent a discovery of nature, such as the genetics of sea life creatures ${ }^{7}$.

Intellectual Property in Biomimicry Research from Sea Life Creatures: Patent granting in biomimicry research from sea life creatures is the importance of its motivation and compensation for the research team's time, expertise, and financial contribution. Creating a novel solution from a natural discovery is a challenging and lengthy process. A case of the underwater forest is a practical example. The sea creates, and the forest ecosystem guides innovation across disciplines, such as medical treatment, climate solution, and industrial food production. However, "a single specimen can generate dozens of strains of bacteria. Screenings are difficult and take months. If a compound passes all the tests, presuming funding continues, they might reach the clinic in 15 to 20 years"4. In short, available research on sea creatures from the initial stage to the publishing can cost a researcher's whole career. To compensate for their time and career, verbal or academic recognition is not enough. With the patent rights, these researchers or institutes can sell their rights or lend to companies for royalties and ensure no one will take their decade research for granted. Moreover, according to BASF experts, "patents secure the underlying investments" 6 . As researchers cannot fund their academic work, they could only use patents as security for attracting investment. Without the exclusive rights to commercialize and protect their research from other people, the researchers would not have the motivation or essential funding to develop medicine and other applications from a sea creature.
Inequality on Patent Grantings In Biomimicry Research From Sea Life Creatures: Unfortunately, the world patents on sea life are not allocated equally worldwide, creating a technical monopoly.Understanding the potential application of sea creatures, BASF Group, a German chemical company and the second-largest chemical producer globally, has researched and patented over 6000 patents related to sea creatures' DNA. They hold $47 \%$ of the 13000 involving the DNA of sea life in 2018- the sign of inequality in marine knowledge ${ }^{6}$. From research and innovation perspectives, BASF creates a legal and commercial barrier that can prevent other entities from taking part in sea life's biomimicry. Firstly, as BASF accumulates half of the global pattern on sea creatures' DNA, they make the future patent process more costly as other innovators must pay BASF for related patents. Secondly, BASF can create a litigation threat for future inventors. Since BASF encompasses various faces of sea creatures' DNA and application method, they have extensive power to sue new inventors on similar technologies or scientific applications. For example, BASF creates an innovative method to apply a gene sequence from a sperm whale into a dairy substitute's manufacturing processes. Hypothetically, researcher Khoa figures out a more suitable gene from another animal and applies a reasonably similar process with BASF. As Khoa's research is more innovative and effective, Khoa would likely face litigation from BASF because this corporation wants to protect its commercial standing. Hence, having one entity with a high share of global patents would lead to technical monopoly and discourage innovation.

Moreover, ten highly developed countries in the global north held $98 \%$ of the patents globally. For experts from the American Association for the Advancement of Science, the problem is also at the inequality allocation of technology between the developed and developing countries ${ }^{3}$. Although there is no direct causal relation between intellectual property rights and global inequality, patents' unequal distribution would create an imbalance between multinational and local companies. Because the patent holders have exclusive rights on their invention for commercial, research, and non-commercial activities, companies from the highly developed nations can exclude other developing nations to access the ocean's economic benefits. These technological and commercial exclusives would not benefit the global society and the sustainable usage of international water. Experts believe that the ocean is beyond any country's 
jurisdiction and the United Nations Convention on the Law of the Sea (UNCLOS) commits to inclusive and transferable marine technology. As countries share the ocean, a patent without commercial binding could benefit the global society and uphold the international marine treaty.

Dicussion on Patent Granting for Marine Discovery and Application on a Legal Perspective: However, having the majority share of global patents on sea creatures is not equivalent to owning the sea. From a legal perspective, the ocean is a library filled with books and knowledge rather than land for occupation. The act of one filling a new patent learned from the library's books does not prevent other people from accessing the library. The United States granted patents for the first person who identified the new gene sequences and entitled him exclusive rights on commercial, clinical, and non-commercial uses for 20 years. However, this rule was over-rule in the United States in 2013. It created a precedent for many other nations 2 . Today for most countries, one cannot patent discovery from nature or the product of nature. In the context of genetics, Mr. Blasiak from Stockholm Resilience Center mentions one can only patent "synthesis organism; a little bit of DNA from a lot of different things." The process of creating a synthesis organism is genuinely an innovative idea, equivalent to building a new car model from various raw materials from nature. A researcher can patent the collective synthesis organism, but he has no exclusive rights to each little bit of DNA from a natural sea creature. For example, genetic sequences from a purple sea urchin have been used by three companies across Germany, the United States, and Japan without any litigation occurring ${ }^{6}$. This is the evidence for the inclusive usage of global sea creatures and other related discoveries about them.

Before the birth of IP rights and patents, companies usually keep their technical research as a trade secret, limiting the knowledge sharing between people to people. The patent also encourages knowledge sharing between business and academics. Technical information disclosure is a mandatory part of patenting an invention. This information will be presented at the marine genetic resources (MGR) for global researchers to learn. In the sea creature context, this can be researched from "species associated with deep-sea hydrothermal vent systems," underwater microbes, ...., which might not be accessible without advanced technology, technical experts, and extensive research time the individual researcher ${ }^{3}$. The technical disclosure also prevents duplication of research effort and encourages building on existing solutions. Hence, the cumulative nature of science would benefit from this treatment.

Moreover, the majority of patents only last for 20 years ${ }^{7}$. After this period, it is free and accessible for the majority of citizens. If there is a technical monopoly, it is just a temporal situation. In the long run, the patents of corporations will become a shared resource for all. Therefore, entities, such as BASF, "could play a very important and valuable role in supporting efforts to ensure that areas beyond national jurisdiction can be accessed by all and benefit all."After analyzing the arguments above, it is more reasonable to grant companies patent rights for their innovative usage and new bio-synthesis inspired by nature. The suggested problems of patent rights could be solved with other solutions rather than eliminating the patent grating system. Firstly, to promote the inclusive usage of international water and its biodiversity, developed countries should support developing countries with cutting-edge facilities to research sea creatures. The support should encompass human capital, financial support, technological transfer, and machinery. With this collaboration, developed countries would also benefit from the unique natural system in developing countries and local expertise. Moreover, if there is sufficient evidence proving that BASF hinders innovation from other marine researchers, UNCLOS and WIPO could reduce the patent periods or redefine the scope of patent owners' exclusive rights. These policies would ensure that patent owners' creativity, works, and commercial rights are respected without compromising future research on sea creatures and biomimicry.

\section{Conclusion}

In conclusion, life underwater is an essential source of future technology and knowledge, such as medical treatment, pain reliever, and many drug inventions. Hence, governments should optimize the legal environment for promoting innovation in this industry. A single company should be allowed to patent an invention related to sea life because the benefits of patent granting overshadow the drawbacks in promoting innovation and research on sea life. To combat the domination of patent-holding, such as in the BASF case, the international government could modify the current patent laws to best fit society's needs. 
Ethical Clearance: Taken from institutional ethics committee.

Source of Funding: Self.

Conflict of Interest: Nil

\section{References}

1. Tollis M, Robbins J, Webb A, Kuderna L, Caulin A, Garcia J et al. Return to the Sea, Get Huge, Beat Cancer: An Analysis of Cetacean Genomes Including an Assembly for the Humpback Whale (Megaptera novaeangliae). Molecular Biology and Evolution. 2019;36(8):1746-1763.

2. Can genes be patented? [Internet]. MedlinePlus Genetics. 2020 [cited 30 October 2020]. Available from: https://medlineplus.gov/genetics/ understanding/testing/genepatents/

3. Kirby A. One Corporation Holds Most of Ocean's Genetic Patents [Internet]. American Association for the Advancement of Science. 2018 [cited 30
October 2020]. Available from: https://www.aaas. org/news/one-corporation-holds-most-oceansgenetic-patents

4. Klein J. A Forest Submerged 60,000 Years Ago Could Save Your Life One Day [Internet]. The New York Times. 2020 [cited 30 October 2020]. Available from: https://www.nytimes. com/2020/03/31/science/underwater-forestshipworms.html

5. Malve H. Exploring the ocean for new drug developments: Marine pharmacology. Journal of Pharmacy and Bioallied Sciences. 2016;8(2):83.

6. Murphy H. What 13,000 Patents Involving the DNA of Sea Life Tell Us About the Future (Published 2018) [Internet]. The New York Times. 2020 [cited 30 October 2020]. Available from: https://www. nytimes.com/2018/09/17/science/patents-marinedna.html

7. What is Intellectual Property (IP)? [Internet]. Wipo. int. 2020 [cited 30 October 2020]. Available from: https://www.wipo.int/about-ip/en/ 